\title{
Resistance, Cooperation and Collaboration with International Development Volunteers: Considering Masculinities and Transnational Feminism
}

\author{
Somed Shahadu Bitamsimli
}

\section{Introduction}

Contemporary studies and scholarship on International Development Volunteers (IDVs) have effectively emphasised their invaluable contribution to promoting Gender Equality and Women Empowerment (GEWE) in partner organizations and communities in the Global South (Tiessen/Rao/Lough 2020; Tiessen/Lough/ Cheung 2018; Butcher/Einolf 2017; Seelig/Lough 2015). Research evidence continues to highlight the transformative potential and mutual benefits of the intercultural interaction between IDVs from the Global North and partner organizations in the South. Staff of partner organizations and beneficiary communities in the Global South consider male IDVs particularly to be key allies in promoting GEWE because they demonstrate alternative (soft) masculine behaviours in their everyday interactions with the local people in ways that have a potential to transform local norms. Whereas these interactions have been mapped as an opportunity to positively transform local gender norms and behaviours, some studies have deployed critical theory to characterize the interaction as an exercise of 'colonial continuity' (Heron 2007) made possible only by the unequal distribution of power.

This paper examines the experiences of partner organization staff as they navigate transnational relationships with IDVs and the delivery of GEWE programming. Findings from this study also highlight experiences of resistance, cooperation and collaboration in the design of gender equality programming. At the heart of this analysis is a focus on agency as expressed through the perspectives of partner organizations who are active agents in navigating programming in collaboration with Global North transnational actors.

To fully explore agency and the experiences of partner organizations in transnational spaces, I apply a theoretical lens that captures the breadth of interactions, reactions and strategies employed. Previous studies have relied heavily on critical theory and neocolonial analyses to consider the transnational spaces where IDVs and partner organizations are operating and the structural limitations (Clost 2014; Simpson 2004; Cook 2007; Baaz 2005; Heron 2007). While these critical insights help understand important challenges and systemic inequalities in development programming, they offer limited insights into the range of experiences of partner organization staff as they negotiate gender equality priorities in line with local 
cultural norms and values and through transnational feminist lenses. This paper analyzes the tensions between agency and critical theory through a transnational feminist lens.

\section{Literature Review}

Critical theory is commonly used in scholarship on international volunteering as a lens to scrutinize North-South relationships with a particular focus on issues of power and privilege as they relate to the experiences of Global North transnational actors engaged in volunteer programs in the Global South. Scholars have used neocolonial interpretations of knowledge exchange to document problematic and inequitable structural processes that are facilitated by neoliberal globalization and that contribute to 'colonial continuities' (Heron 2007; Loiseau et al. 2016; Perold et al. 2013; Baaz 2005). Post-colonial theory has often been deployed in this sense to highlight how colonial and post-colonial imaginaries of development are reinforced in the process of international volunteering. Critical theory scholars have used colonialism and neo-imperialism as entry points to explain the underlying structural dynamics that produce and reproduce unequal international relations that largely serve the strategic interests of Northern governments and Global North citizens at the expense of the Southern 'others' (Clost 2014; Simpson 2004; Tiessen/Kumar 2013; Cook 2007; Baaz 2005; Heron 2007).

Although neocolonial analyses offer a valuable critical examination of structural limitations to equality through the colonial continuities of North-South relations, they fall short of exploring the agency and voices of partners in the Global South and are thereby "limited in their ability to decolonize the scholarship on international volunteers (Tiessen/Lough/Cheung 2018:11) and insufficient to explore the relational aspects of international development volunteering (Tiessen/Rao/Lough 2020; Palacios 2010; Devereux 2010; Howes 2008).

In comparison with neocolonial and critical analyses, a more comprehensive analytical lens that focuses on transnational spaces where IDVs and partner organization staff work together to negotiate and navigate structural realities and local priorities is necessary for understanding strategies employed or resisted as part of GEWE programming. The analytical lens of transnational feminism fills some of these gaps. Therefore, the analytical lens of transnational feminism is employed in this paper to consider the unique contributions of transnational actors such as IDVs in their interactions with Global South partners. A transnational feminist lens highlights the importance of understanding agency and the perspectives of partner organization staff, including their needs, preferences, perceived outcomes and the value attached to interpersonal dynamics (Tiessen/Lough/Cheung 2018; Butcher/ Einolf 2017; Seelig/Lough 2015). 
Transnational feminism stems from a renewed urgency to uphold the principles of gender equality, justice, and fairness building on feminist interpretations of gender equality. Transnational feminism combines alliance-building strategies across cultural differences with local level insights on cultural specificity as Global South scholars and activists turn their attention to dismantling patriarchy in their own nations and regions (Quataert 2014). Transnational feminism builds on the work of African feminists, specifically scholars who have challenged the systematic domination of women by men in some or all of society's spheres and institutions (Walby 1997; hooks 2004). African feminist theorising and activism have both influenced and brought to the fore critical debates on gender and intersectional politics (Oyěwùmí 2003; Tamale 2011; Ratele 2013), and put women's agency at the centre of the discussion. As such, applying a transnational feminist lens advances knowledge of agency and structural inequality and how these relate to local feminisms, empowerment, and transnational relationships.

When assessing gendered transnational relations, little has been written about the influence of IDVs. IDVs, as transnational actors working in the Global South, offer avenues for new synergies in their relationships with partner organization staff to collectively unpack everyday issues that may be unchallenged such as power dynamics, gender relations, and root causes of inequality (Lough/Tiessen 2016; Schech et al. 2019; UNV 2015). The relationship between IDVs and partner organization staff in this process of making sense of gender inequality exposes tensions and mutual learning that arise from a partnership model of reflecting on power dynamics in GEWE programs. The design of GEWE programs between IDVs and partner organization staff is, however, fraught with tensions and resistance. Understanding the reason for resistance is important for considering the possibilities for - and limitations of - GEWE programming.

Through sustained relationships between IDVs and partner organization staff, the scope for mutual learning grows and thereby the opportunities for transnational feminist values to be asserted and enacted in these transnational spaces also grows. Transnational feminism offers new insights into alternative interpretations of feminism and gender equality, highlighting ways of being and knowing that place equal importance on subaltern voices and ensuring the discursive space to deconstruct and reconstruct local values. Transnational feminism fosters a better understanding of thematic and conceptual notions that underpin international development volunteering, and commitments to reciprocity, mutuality, and intercultural competencies, as well as ethics and social justice. Next, I examine the experiences of partner organization staff who navigate GEWE programming priorities introduced by IDVs: their reactions, resistance, and reflections on finding common ground when working in partnership with IDVs. 


\section{Methods}

Interviews were conducted in 2018 - 2019 with 150 partner organization staff in ten countries. Once all interviews were transcribed, data were coded to identify common themes throughout. Data were analyzed using discourse analysis. The introduction to this special edition has more detailed information on the methodology for data collection and the analysis of findings.

\section{Conservative Values and Resistance to Change}

Data collected from the ten countries assessed in this study advances our understanding of how the transnational interactions and engagements between IDVs and staff of partner organisations help to dismantle and challenge negative cultural norms and gender stereotypes that undermine the success of GEWE initiatives. Two core findings across the sample help us understand the way that GEWE is understood and interpreted within local contexts: conservative values and resistance to change and respecting local culture and re-imagining GEWE in local contexts. The cross-cultural opportunities offered by international volunteering have often been leveraged by partner organizations to help improve the understanding of their staff and beneficiary communities about alternative norms and transformative cultural practices that can enhance gender equality. The two themes that emerged from this analysis will be discussed in turn. This paper first looks at conservative values and resistance to change, and then turns to a discussion of respecting local culture and re-imagining GEWE in local contexts.

GEWE programs introduced by or facilitated through the work of IDVs can provoke hostilities and resistance from a small, but often powerful, group of people within the partner countries. Conservative voices and patriarchal gatekeepers in the Global South often invoke culture and tradition as the pretext to reject GEWE programming. Those who resist GEWE initiatives may view these programs as externally imposed by Western powers. Such a view shows little understanding of the locally-based feminists (men, women, transgender, and non-binary) fighting for gender equality and women's rights in their own communities, including scholars, human rights defenders and civil society organizations (Kapur 2005; Mohanty 2003; Quataert 2014; Okech/Musindarwezo 2019).

Respondents in this study highlighted culturally grounded hegemonic masculine practices as one of the major challenges towards implementing GEWE initiatives. These problematic masculine behaviours and patriarchal hostilities are a constant distraction that reify a kind of resistance to GEWE, framed around a particular narrow and largely uninformed or uneducated claims of culture and traditions that wilfully ignores systemic inequality. For instance, a male senior administrator at one of the partner organizations in Kenya, elaborated on what he has observed 
from community members as forms of distrust for GEWE programming as a Western imposition, asserting cultural expectations of men's roles as leaders and heads of the family:

The challenges are we have what we call conservatives. Some of them are those conservatives who believe that the man is the head and women are not supposed to lead. They still live in the old schools of thought...

These understandings of patriarchal norms are often linked to patriarchal structures resisting GEWE, and any kind of social change that would undermine male privilege thereby threatening these structures. As another staff member from Kenya noted:

African traditions are a patriarchal society where men are very dominant and anything that goes like women are trying to come to the same level through equality and all that then there is a lot of resistance in this community.

Patriarchal expectations of the gender division of labour are further understood as a barrier to women's economic opportunities. For example, an interviewee in Vietnam noted:

At the family level, there are some barriers for women in businesses. Many men want women to stay home and spend more time with the family, taking care of children. They do not support women with business. That kind of challenge still exists in Vietnam.

Understanding local hostility to GEWE is important to inform better education and awareness about women's rights and feminist principles. The resistance against GEWE can be viewed as the manifest reaction of patriarchy to the potential changes in gender relations, which is often felt as disruptive in people's lives as well as local beliefs and customs. Resistance to gender equality (GE) can generally be understood as active resistance and passive resistance. Respondents described active forms of resistance to involve openly challenging the goal or relevance of GEWE, putting forward alternative facts and arguments against it, and often trying to persuade others to join the opposition. Passive resistance on the other hand is often difficult to detect and can even go undetected depending on the resistor's proximity to power. It may take time to discover passive resistance against implementing GE programs because the people involved are often part of the GE project. They pretend to be supporters of gender equality, but in reality, their deeper feelings oppose the idea. Such saboteurs apply their subtle acts in their own work within the organizational set up, and quietly undermine or sabotage the implementation of gender policies or programs. Others may say they support gender equality but point out that there are more urgent and pressing priorities to be addressed first. One male project administrator in Ghana raised this point during the interviews: 
The men are saying that any work that comes to the community is focusing on empowering women but then there are vulnerable men. Women in some of these communities are more empowered than some men in that community and for that matter we should begin to see beyond just gender.

As revealed by the data in this study, the major factors responsible for slowing the progress in achieving GEWE goals are: the misinformed nature of these perspectives, coupled with limited understanding of the essence for GEWE to be women-focussed to a large extent, and their lack of understanding of systemic inequality and how it disproportionately leads to discrimination against both men and women.

Staff working on GE projects have also highlighted the threat of deeply-held misogynistic, sexist and patriarchal behaviours that undermine the success of gender-specific development programs. One of these challenges is the persistence of hegemonic practices that legitimizes male superiority in all aspects of social relationships in the private and public sphere, the first of which are the social norms and practices that normalize male privilege, whereby families train boys to be future leaders and breadwinners, and girls to be future subordinated dependents of men. The consequence is lack of paid job opportunities to earn income, while men dominate both private and public sector work. Although many women have entered the workforce and may also be heads of households and breadwinners, the vision of domestic life, which continues to dominate the imagination of many cultures, is one in which the logic of male domination is intact, whether men are present in the home or not (hooks 2014). One male staff member of a partner organization raised this point in Kenya:

African traditions are a patriarchal society where men are very dominant and anything that goes like women are trying to come to the same level through equality and all that then there is a lot of resistance in this community.

Revolutionary feminist consciousness-raising emphasized the importance of learning about patriarchy as a system of domination, how it became institutionalized and how it is perpetuated and maintained. "Understanding the way male domination and sexism was expressed in everyday life would awaken women to the realities of their victimization and exploitation by the patriarchal structures" (hooks 2014:7). Women who defy the odds and make it into professional careers or seek to make their own income always risk the triple role burden imposed by the patriarchal gender order, whereby women must combine productive, reproductive, and community obligations along with other duties such as being a 'good housekeeper' (family welfare and harmony), which also add other layers of responsibility on the woman. This may be partly responsible for the lack of progress in breaking the glass ceiling for many women, as explained by one respondent from Nepal: 
I think an employer will always seek a male employee instead of a female. He will look for male not female. They are very much thinking that the female will get married and go to the husband's house, much less time at the office and work.

In most of the other countries where data was collected for this study, similar concerns of discriminatory practices limiting women's access to resources and paid employment opportunities arose. For example, in Kenya, one participated noted:

When a woman is married, she has to go to her husband's home. It does not matter if she is a working woman or someone who does not work, she has to do all the home activities, she has all the responsibility. All the responsibilities at home and at work.

Sexist and discriminatory views translate into discriminatory practices. For example, men are more dominant in the business community and are more likely to serve on boards and decision-making bodies. This results in significant barriers to women's participation in new start-ups and, as one person in Vietnam noted, it is therefore "difficult for women to join the investing world. Some start-up women say that they had difficulty in accessing investors."

Adding an intersectional lens, it is clear that gender inequality can be more significant among certain ethic groups. As another organization partner from Vietnam notes:

For certain ethnic minorities, the men control all the business in the family. If someone comes to the house, he is expected to approach first. If you bring women outside the house, men need to be consulted.

Similarly, in Nepal, challenges arise in terms of gender inequality and ethnic minority groups as one organizational staff member added:

Working with ethnic minority female students is very challenging when they tend to get married so young. There exist social norms in the mountainous areas that they do not want girls to study further, they will create more opportunities for boys.

These patriarchal norms and cultural practices within many countries make tackling gender inequality a complex and challenging endeavour. The interview participants provided many examples of the specific challenges they encounter; the resistance they met from different members of the community (primarily men in positions of leadership, but also women who seek to uphold cultural values as a means to maintain social and family cohesion). Despite experiences of resistance to change, gender norms, and cultural practices are dynamic (Okech/Musindarwezo 2019; Ahmed/Meena 2012). 


\subsection{Respecting Local Cultures and Re-Imagining GEWE in Local Contexts}

Several study participants noted that a lack of cultural understanding by some IDVs have negative ramifications on the impact they make, emphasizing that the lack of cultural knowledge is a serious limitation for IDVs in promoting GEWE. Others suggested the need to withdraw IDVs from the frontlines of promoting gender equality, and rather restrict their role to training local staff of partner organizations who, in their view, would be better positioned to navigate the potential conflict or tensions associated with promoting GE in a patriarchal society.

One of the core findings across the ten countries was the emphasis on creating buy-in among men of GEWE programming. As previous scholars have argued, dismantling and changing patriarchal gender order will require both men and women to work together (hooks 2004). Without men and boys as allies in the struggle, the feminist movement will not progress because it would be a missed opportunity to work together to correct the assumptions deeply embedded in the cultural psyche that feminism is anti-male. IDVs are seen as playing a vital role in promoting increased involvement of men in GEWE programs. One example that was mentioned by several study participants was the significance of having men IDVs engaged in GEWE work as a way to promote alternative masculinities and break down gender barriers, especially when it comes to the gender division of labour.

While hegemonic masculine norms may oppress local men, who would otherwise wish to express equality in their relationships by performing roles normally assigned to women, male IDVs remain one of the key conduits through which alternative masculine ideas can be demonstrated or practiced. Whereas it is no longer a strange phenomenon in Western societies for a man to participate in basic household chores (e.g. cooking, washing dishes or cleaning the house), local men in patriarchal societies often risk consequences if they transgress these socially constructed gender barriers. Most GEWE projects consider IDVs to be allies and role models because they demonstrate alternative masculinities that can transform gender relations within the workspace and in beneficiary communities. The following are some of the ways participants perceived to be positive promotion of alternative masculine norms. For example, a study participant in Kenya explained: "One example is that they even helped to change babies' diapers. He actually helped to do that. It looked like ooh no this is a woman's job, but he did it.”

In Kenya, some partners also perceive IDVs to have influenced their community to change perceptions about gender norms. This is usually the case when male volunteers often take up traditionally female roles such as doing household chores. The host organizations and communities in the South draw inspiration from the 
exemplary gender-sensitive behaviour of IDVs, a situation that enhances the possibility of equal division of labour between men and women.

We learned some things from them [IDVs]. In Africa [and] Kenya gender roles are so divided, and it is almost like a taboo for men to do some things like even carry a child. We learned that what a man can do, or a woman can do; we can collaborate and just do everything together.

Similarly, in Ghana, one participant shared: “There are certain things we say is a woman's thing but from the volunteer's behaviour for example, he washes his own plate after he's done. The people are surprised that he would do his own stuff."

Some feminist organizations and GEWE advocates consider IDVs as allies because their presence in workspaces and communities provide an alternative approach that positively transform gender norms and problematic masculine behaviours. In Ghana, participants explained that "When you are a woman in our community, and you are talking about gender equality you look very strange to your male counterparts. But somebody from another culture brings that [and] it helps.” Likewise in Kenya, partner organization staff consider outsiders' perspectives helpful for explaining why violence against women is a violation of human rights. In Tanzania, partner organization staff used examples of the country's commitments to United Nations resolutions and national policy documents as further evidence that practices such as violence against women were not acceptable in the country.

The day-to-day actions of IDVs were often perceived as fresh perspectives on alternative roles carried out by men and women. Through these observations, IDVs were able to break down barriers and rethink what is normal practice. While important opportunities for alternatively role modelling on gender roles was highlighted by several staff members across a number of countries, other ongoing challenges for addressing GEWE were explained in terms of perceptions of leaving men and boys behind. Concerns about perceived special treatment for women highlighted resentment and hostilities towards GEWE initiatives. These concerns ranged from specific complaints about the lack of attention to male poverty and vulnerability to fears that GEWE is a zero-sum game calculated to disempower men. In Ghana, one participant described the concerns as a form of backlash:

The men are saying that any work that comes to the community is focusing on empowering women but then there are vulnerable men also and that IDVs are too focused on women and leave out men.

Some respondents in Kenya echoed these concerns of GEWE programming being too focused on women and girls, while livelihood opportunities are increasingly becoming scarce for many boys and men who are equally vulnerable. A male GEWE program officer from Uganda emphasised the need for GEWE programmes 
to advocate for mutual understanding and cooperation between men and women instead of focussing on women and girls' empowerment. In his view, GEWE programs run the risk of creating "a generation where women are more empowered than men... then we would need to go back to fighting for the rights of men."

Another respondent from Malawi echoed this view: "If it keeps pushing men away from taking on leadership roles then I feel like in the future is going to become another problem. So having a balanced set up is more ideal."

\section{Analysis}

Two main points can be deduced from these voices: the first is the significance of increasing the participation of men and boys as a means of promoting local acceptance and consensus on gender equality programs. The second, however, is an erroneous perception that women's empowerment automatically results in men's disempowerment. As noted earlier in the introduction, such problematic perceptions of feminism and GE serve as acts of resistance to the meaningful changes that are needed. Power in this context is seen as a zero-sum game whereby power won by some results in power taken from others. Education to promote a better understanding of empowerment as a universal goal is important, and that needs to start with the messaging.

Others see engaging men and boys as a critical factor to the success of GEWE, recognizing that men are part of the problem. In this view, boys and men can be useful allies in finding a solution. The participation of men and boys in support of gender equality has the potential to bring positive changes in their attitudes, perceptions and behaviours that benefit women and girls (Lang 2003; Flood 2007; Silberschmidt 2011). Engaging men and boys is also important because understanding men's gender expectations - their expected roles, relations and positions as men - can help engage them more naturally in efforts to curb masculine-related violence, achieve equality and reduce poverty (Lang 2003). IDVs also play a crucial role in supporting gender equality programming that promotes men's participation in gender equality.

It is also important to highlight the sentiments of mutual complementarity expressed in the subaltern perspectives presented in these findings; they reinforce the fact that volunteer projects that are designed to accomplish a common social goal like gender equality, and involve multiple ethnic groups, have the potential to break down barriers that separate diverse ethnic and social groups. Partner organizations, beneficiary communities, and local feminist groups regard IDVs as critical allies in the struggle against patriarchal resistance towards GE, which often manifests in the form of toxic or problematic masculine behaviour. IDVs' cross-cultural knowledge and understanding, as well as their inclination to bring social justice perspectives when discussing issues of GE, make them crucial enablers of 
otherwise nonexistent safe spaces to deconstruct local gender norms in ways that can lead to change in mindsets and attitudes towards GEWE. IDVs bring diverse perspectives that contribute to increased tolerance and broadened perspectives on how to solve problems, especially involving gender relations. They help to develop human resources of partner organizations by contributing skills, information, and knowledge to support organizational capacity building. IDVs help to increase the ability of partner organizations to successfully design programs and deliver GEWE programs. Volunteering for development, especially in the area of gender equality and women's empowerment, has contributed significantly to improving women's skills, understanding of their rights, and decision-making power.

Although challenges remain in how the cross-cultural interaction between the North and the South is structured, the Southern voices presented in this project provide a counterpoint to post-colonial and neoliberal critiques (Cook 2007; Baaz 2005; Haas/Georgeou 2019; Georgeou/Engel 2011; Lyons et al. 2012; Simpson 2004; Heron 2007). Post-colonial and neoliberal critique may inaccurately characterize subaltern actors as powerless and passive recipients of Northern aid tied to a Western conception of being (Tiessen 2018; Lough 2011; Lough 2013; Lough 2019). The direct contact among people from different backgrounds has the potential to make people more comfortable with each other's differences, to reduce anxiety, and to lead to mutual understanding and respect (Tajfel/Turner 1979).

Further investigation is required to fully uncover the specific ways in which IDVs and partner organizations navigate their cultural differences to promote GEWE. However, the partnerships forged through IDV creates transnational spaces across the local-international divide that are crucial to achieving international targets and realizing commitments to gender equality. To effectively harness the potential in these partnerships, researchers and development workers must recognize and acknowledge both the potential dominant Westernized perception and imposition of GE, as well as the potential for new knowledge production and contributions to solidarity movements. Transnational feminism is the most suitable lens through which one can make sense of the impact IDVs make in promoting GE. The application of this lens examines the relationship between a politics of location and accountability, and the politics of knowledge production by examining the histories and hierarchies of power and agency. Some feminist scholars have also defined the transnational in relation to women's cross-border organizing (Mindry 2001; Mohanty 2003), and as a spatialized analytic frame that can account for varying scales of representation, ideology, economics, and politics, while maintaining a commitment to difference and asymmetrical power (Radcliffe et al. 2003).

Deconstructing and transforming gender relations is likely to be limited in scope and impact unless gender equality programs adequately recognize, and engage with, the complexities and situational realities of men and masculinities in diverse 
spaces. Evidence continues to highlight different ways in which men's entanglement with dominant masculinities make men profoundly vulnerable and expose women to negative acts and behaviours (Clowes 2013; Ratele 2013). The southern voices in this research and in previous studies have emphasized that excluding men, boys, and notions of masculinities from feminist work risk producing limited and unsustainable outcomes (Morrell/Jewkes/Lindegger 2012; Greig/Edstrom 2012; Ratele 2014). A transnational feminist lens offers an alternative approach to examining patriarchy and masculinities in cross-cultural contexts. It reaffirms the importance of engaging men and boys in feminist practices and GEWE programming, while also exposing the dangers and consequences of patriarchy to individual men and women (hooks 2004).

\section{Conclusion}

The findings outlined in this paper document the important role IDVs can play in building crucial relationships that enhance the capacity of locally based staff to undertake GEWE projects. The relationships that IDVs forge with partner organization staff can also generate new opportunities to interrogate local norms and to unpack cultural practices that undermine GEWE. These observations also echo the findings by Rao/Tiessen/Lough (2020) that IDVs have helped staff members of partner organizations to gain increased confidence to openly discuss gender-related matters such as gender-based violence, family planning, and sexual behaviors. Without the cultural disruption caused by volunteers, many of these issues are otherwise considered to be either sensitive or an abomination to talk about in the local culture.

Despite the power inequality and cultural conflict highlighted in critical scholarship about international volunteering, this paper finds the cross-cultural contact between IDVs and partner organizations to represent a significant value and longterm support for the host organizations. These exchanges are not merely in the form of unidirectional aid from IDV; they thrive on reciprocal relations of mutual learning. The reciprocity and mutuality in these interactions narrow the cultural gap and strengthen North-South relations. This observation is consistent with contemporary scholarship on the impact of international volunteering (Lough et. al. 2011; Graham, et. al 2012; Burns/Howard 2015; UNV 2015; Butcher/Einolf 2017; Tiessen/Rao/Lough 2020). When understood as a relational and collaborative endeavour this draws our attention to the potential of international volunteering. These transnational collaborations are critical to turn international targets and commitments to GE into practical action (Rao/Tiessen 2020). Transnational feminism negates the inherent contradictions and limitations in feminist processes where 'difference' is based on external standards and is therefore viewed as an external frame of reference (Okech/Musindarwezo 2019). 
IDVs are therefore seen as important allies whose presence in partner countries helps to create intercultural exchanges and interactions that have the potential to transform gender norms and to model alternative masculine behaviours that support the values projected by GEWE initiatives. IDVs are therefore crucial transnational change agents who contribute to GEWE outcomes. This empirical research fills an important gap in the literature in the examination of norm changes from both sides of the volunteerism relationship (Schech et al. 2019; Tiessen/Rao/ Lough 2020). Improved knowledge outlining how attitudes and behaviours change can help uncover the spaces where transformations in gender relations happen and can open new opportunities to build long-term and sustainable gender equality programming, while also broadening our knowledge on the ways in which volunteers and staff from overseas interact, engage, and dialogue in everyday settings (Loiseau et al. 2016; Tiessen/Rao/Lough 2020).

The interaction and exchange between international volunteers and local communities have been linked to increased confidence among partner staff members when it comes to gender-related issues, especially when speaking about sensitive topics like gender-based violence, sexual behaviors, or family planning (Rao/Tiessen 2020). In the words of one respondent in Ghana, IDVs bring a distinct value system which encourages transformative thinking and inclusive approaches that improve gender relations and social cohesion. They bring different views and perspectives that enable local development organizations to provide opportunities that can create change in attitudes and behaviours towards gender equality.

\section{Bibliography}

Ahmed, Aziza; Meena, Seshu (2012): We have the right not to be 'rescued': When anti trafficking programmes underline the health and well-being of sex workers. In: Anti-Trafficking Review, vol. 1, no. 103, pp. 149-168.

Baaz, Maria Erikson (2005): The Paternalism of Partnership. A Postcolonial Reading of Identity in Development Aid. New York.

Burns, Danny; Howard, Jo (2015): Introduction. What is the Unique Contribution of Volunteering to International Development? In: IDS Bulletin, vol. 46, no. 5, pp. 1-4.

Butcher, Jacqueline; Einolf, Christoph (2017): Perspectives on volunteering. Voices from the South. New York.

Clost, Ellyn (2014): Visual Representation and Canadian Government-Funded Volunteer Abroad Programs: Picturing the Canadian Global Citizen. In: Tiessen, Rebecca; Robert Huish (ed.): Globetrotting or Global Citizenship: Perils and Potentials of International Experiential Learning. Toronto, pp. 230-258.

Clowes, Lindsay; Ratele, Kopano; Shefer, Tamara (2013): Who Needs a Father? South African Men Reflect on Being Fathered. In: Journal of Gender Studies, vol. 22, no. 3, pp. 255-267.

Cook, Nancy (2007): Gender, Identity and Imperialism. Women Development Workers in Pakistan. New York. 
Devereux, Peter (2010): International volunteers. cheap help or transformational solidarity toward sustainable development. Murdoch University.

Flood, Michael (2007): International encyclopedia of men and masculinities. London.

Georgeou, Nichole; Engel, Susan (2011): The impact of neoliberalism and new managerialism on development volunteering. An Australian case study. In: Australian Journal of Political Science, vol. 45, no. 2, pp. 297-311.

Georgeou, Nichole; Haas, Benjamin (2019): Power, Exchange and Solidarity. Case Studies in Youth Volunteering for Development. In: Voluntas, vol. 30, no. 6, pp. 1406-1419.

hooks, bell (2004): The will to change. men, masculinity, and love. New York.

Howes, Andrew (2008): Learning in the contact zone. Revisiting neglected aspects of development through an analysis of volunteer placements in Indonesia. In: Compare, vol. 38, no. 1, pp. 23-38.

Heron, Barbra (2007): Desire for development. Whiteness, gender and the helping imperative. Waterloo.

Kapur, Ratna (2005): Erotic Justice. Law and the New Politics of Postcolonialism. London.

Lang, James (2003): Evolving the gender agenda - men, gender and development organisations. http://www.un.org/womenwatch/daw/egm/men-boys2003/EP10-Lang.pdf (14.05.2021).

Loiseau, Bethina; Sibbald, Rebekah; Abdul Raman, Salem; Darren, Benedict; Loh, Lawrence; Dimaras, Helen (2016): Perceptions of the role of short-term volunteerism in international development. Views from volunteers, local hosts, and community members. In: Journal of Tropical Medicine, pp. 1-12, doi:10.1155/2016/2569732.

Lough, Benjamin James; Tiessen, Rebecca (2016): Theoretical alternatives to deconstructive analysis of volunteering for development. Paper presented at the 12th international conference of the International Society for Third Sector Research. Stockholm.

Lough, Benjamin James (2011): International volunteerism in the United States, 2008. In: Center for Social Development, vol. 10, no. 11, pp. 1-8. www.scribd.com/doc/33744391/ International-Volunteering-from-the-United-States (14.05.2021).

Lough, Benjamin James (2013b): Measuring and Conveying the Added Value of International Volunteering. Strasbourg.

Lyons, Kevin; Hanley, Joanne; Wearing, Stephen; Neil, John (2012): Gap year volunteer tourism. Myths of global citizenship?. In: Annals of Tourism Research, vol. 39, no. 1, pp. 361-37.

Mindry, Deborah (2001): Nongovernmental Organizations, 'Grassroots,' and the Politics of Virtue. In: Signs, vol. 26, no. 4, pp. 1187-1211.

Mohanty, Chandra (2003): Feminism without Borders. Decolonizing Theory, Practicing Solidarity. Durham.

Okech, Awino; Musindarwezo, Dinah (2019): Transnational feminism and the post-2015 development agenda. In: Soundings, vol. 71, no. 71, pp. 75-90.

Oyěwùmí, Oyeronke (2003): African Women and Feminism Reflecting on the Politics of Sisterhood. New York.

Palacios, Carlos (2010): Volunteer tourism, development and education in a postcolonial world. conceiving global connections beyond aid. In: Journal of sustainable tourism, vol. 18 , no. 7 , pp. $861-878$. 
Perold, Helene; Graham, Lauren; Mavungu, Eddy Mazambo; Cronin, Karena; Muchemwa, Learnmore; Lough, Benjamin J. (2013): The colonial legacy of international voluntary service. In: Community Development Journal, vol. 48, no. 2, pp. 179-196.

Quataert, Jean (2014): A knowledge revolution. Transnational feminist contributions to international development agendas and policies, 1965-1995. In: Global Social Policy vol. 14, no. 2, pp. 209-227.

Rao, Sheila; Tiessen, Rebecca (2020): Whose feminism(s)? Overseas partner organizations' perceptions of Canada's Feminist International Assistance Policy. In: International journal, vol. 75, no. 3, pp. 349-366, https://doi.org/10.1177/0020702020960120.

Ratele, Kopano (2014): Currents against Gender Transformation of South African Men. relocating Marginality to the Centre of Research and Theory of Masculinities. In: NORMA, vol. 9, no. 1, pp. 30-44, https://doi:10.1080/18902138.2014.892285.

Ratele, Kopano (2013): Masculinities without tradition. In: Politikon, vol. 40, no. 1, pp. 133-156.

Schech, Susanne; Skelton, Tracey; Mundkur, Anuradha; Kothari, Uma (2019): International volunteerism and capacity development in nonprofit organizations of the global south. In: Nonprofit and Voluntary Sector Quarterly, vol. 49, no. 2, pp. 252-271, https://doi. org/10.1177/0899764019867774.

Seelig, Vera; Lough, Benjamin J. (2015): Strategic directions for global research on volunteering for peace and sustainable development. In: Workshop report, CSDWorkshop Report, no. 15-45, pp. 1-13, https://doi.org/10.7936/K7JQ10J0.

Silberschmidt, Margrethe (2011): What would make men interested in gender equality. In: Cornwall, Andrea; Edström, Jerker; Greig, Alan (ed.): Men and Development - Politicizing Masculinities. London, pp. 98-110.

Simpson, Kate (2004): Doing development. The gap year, volunteer-tourists and a popular practice of development. In: Journal of International Development, vol. 16, no. 5, pp. 681692.

Tamale, Sylvia (2011): African Sexualities. A Reader. Nairobi.

Tajfel, Henri; Turner, John (1979): An integrative theory of intergroup conflict. In: W. G. Austin; S. Worchel (ed.): The social psychology of intergroup relations. Monterey, pp. 94-109.

Tiessen, Rebecca; Kumar, Paritosh (2013): Ethical Challenges Encountered on Learning/Volunteer Abroad Programs for Students in International Development Studies in Canada: Youth Perspectives and Educator Insights. In: Canadian Journal of Developing Studies, vol. 43, no. 3, pp. 416-430.

Tiessen, Rebecca; Lough, Benjamin J.; (2018): Introduction. A theoretical and methodological case for examining agency and power relations in North-South volunteering research collaborations. In: Tiessen, Rebecca; Lough, Benjamin J; Grantham, Kate (ed.): Insights on International Volunteering. Perspectives From The Global South. Germany, pp. 7-22. https://dx.doi.org/10.5771/9783845283920-7.

Tiessen, Rebecca (2018): Learning and volunteering for development. Unpacking host organization and volunteer rationales. London.

UNV (2015): Volunteering to advance gender equality. New perspectives for the post2015 agenda. https://www.unv.org/news/volunteering-advance-gender-equality-newperspectives-post-2015-agenda (28.10.2021).

Walby, Sylvia (1997): Gender transformations. London. 